\title{
Sixth Class Students' Performance and Confidence Levels Before and After Training in Clinical Skills Laboratories
}

Ali Mustafa Abualhayja'a, ${ }^{1}$ Handan Ankarali, ${ }^{1}$ Ramez Alyacoub,, Ala' Abudayeh, ${ }^{1}$ Sara Alsaoud, ${ }^{1}$ Omar Majed Alsaeidi, ${ }^{1}$ Moaath Alsmady, ${ }^{1}$ Islam Massad, ${ }^{1}$ Orhan Alimoglu.

\begin{abstract}
Background: Acquisition of basic clinical skills by undergraduate medical students is becoming of greater concern. Clinical skills laboratories may provide a comfortable environment for training and may allow students to gain adequate performance level. The aim of this study is to evaluate students' performance and confidence levels before and after training of selected procedural skills; also to explore students' expectation towards skills laboratory training. Methods: Two questionnaires were conducted before and after training sessions in the clinical skills laboratory, school of medicine, University of Jordan, Amman, Jordan. The skills selected for this study: suture practice, venous access, arterial access, intradermal and intramuscular injection, central venous cannulation, male and female urinary catheterization, nasogastric tube placement and rectal examination. Although fifty-seven 6th year medical students filled the first questionnaire at the beginning before training, only 29 students could attend all training sessions, and fill the second questionnaire. Results: For all trained clinical skills, the mean students' performance scores and confidence levels were significantly increased after training ( $P<0.001)$. Expectations of students for skills laboratory were high. Conclusions: The students' performance and confidence levels were significantly improved after training in the clinical skills laboratory.
\end{abstract}

Keywords: Clinical skill; Undergraduate medical education; Simulation Training; Medical Students (Source: MeSH-NLM).

About the Author: Ali Mustafa Abualhayja'a is currently a 4th year medical student of School of Medicine, University of Jordan, Amman, Jordan of 6 year program.
Editor: Robert Ta. Submission: 2016-08-10

Acceptance: 2017-06-12

Process: Peer-1

\section{Introduction}

The teaching of basic medical knowledge and acquiring the essential clinical skills are important aspects of professional medical practice. ${ }^{1}$ After being taught the basic medical knowledge during the pre-clinical phase, the students learn the practical clinical skills by interacting with patients throughout clerkships and clinical rotations during their clinical years. The purpose of the medical curriculum is to allow the students to gain the knowledge, clinical skills and values required for their practicing medical career. ${ }^{2}$

In fact, mastering the basic clinical skills might require adequate opportunities to practice these skills and longer actual clinical, especially inpatient, encounters. ${ }^{3-4}$ This is largely limited by time and availability of patients. ${ }^{5}$ Furthermore, studies showed that students cannot depend only on clerkships' observations to perform clinical skills competently. ${ }^{6-8}$ Therefore, practical training at clinical skills laboratories (CSLS) has gained greater importance in the medical curriculum. 9-10

In the recent years, CSLs have been established in many medical schools around the world ${ }^{11-12}$ as they have become an essential part of the training program. ${ }^{13}$ They provide a safe environment and allow forgiveness for the missteps that students may make during procedural skills training prior to real-life practice. ${ }^{14-15}$ In addition, CSLs allow students to learn from mistakes as they perform the first clinical skills on manikins. ${ }^{14}$ they create a comfortable environment for tutors to demonstrate the clinical procedures step-by-step and to give students the opportunity of performing the skills using manikins ${ }^{16}$ as well as repeating them until reaching a good performance level. ${ }^{17}$ All of these advantages provide optimal training and preparation for clerkships. ${ }^{7,} 18$

The aim of this study is to determine the effectiveness of CSLS on undergraduate medical students assessing their performance and confidence levels, before and after training of some selected procedural skills. In addition, students' expectation and attitude towards CSLs were investigated.

\section{Methods}

Evaluation of a training program designed to increase clinical skills on medical students. In the fall of 2015 (NovemberDecember), all $(n=57)$ 6th year medical students, who were in the beginning of their surgical clerkship, were invited to participate in clinical skills training. The study was approved by the Institutional Review Board of Jordan University School of Medicine.

\section{Participants and setting}

The medical curriculum at the university is divided into two parts: teaching the basic sciences during the first three preclinical years and learning of clinical sciences during clerkships at the last three years. Students directly enroll into clinical rotations after they complete learning the basic sciences.

School of Medicine, University of Jordan. 
Figure 1. Students' expectations towards skills laboratory before training $(n=57)$ (My expectations for skills laboratory training are)

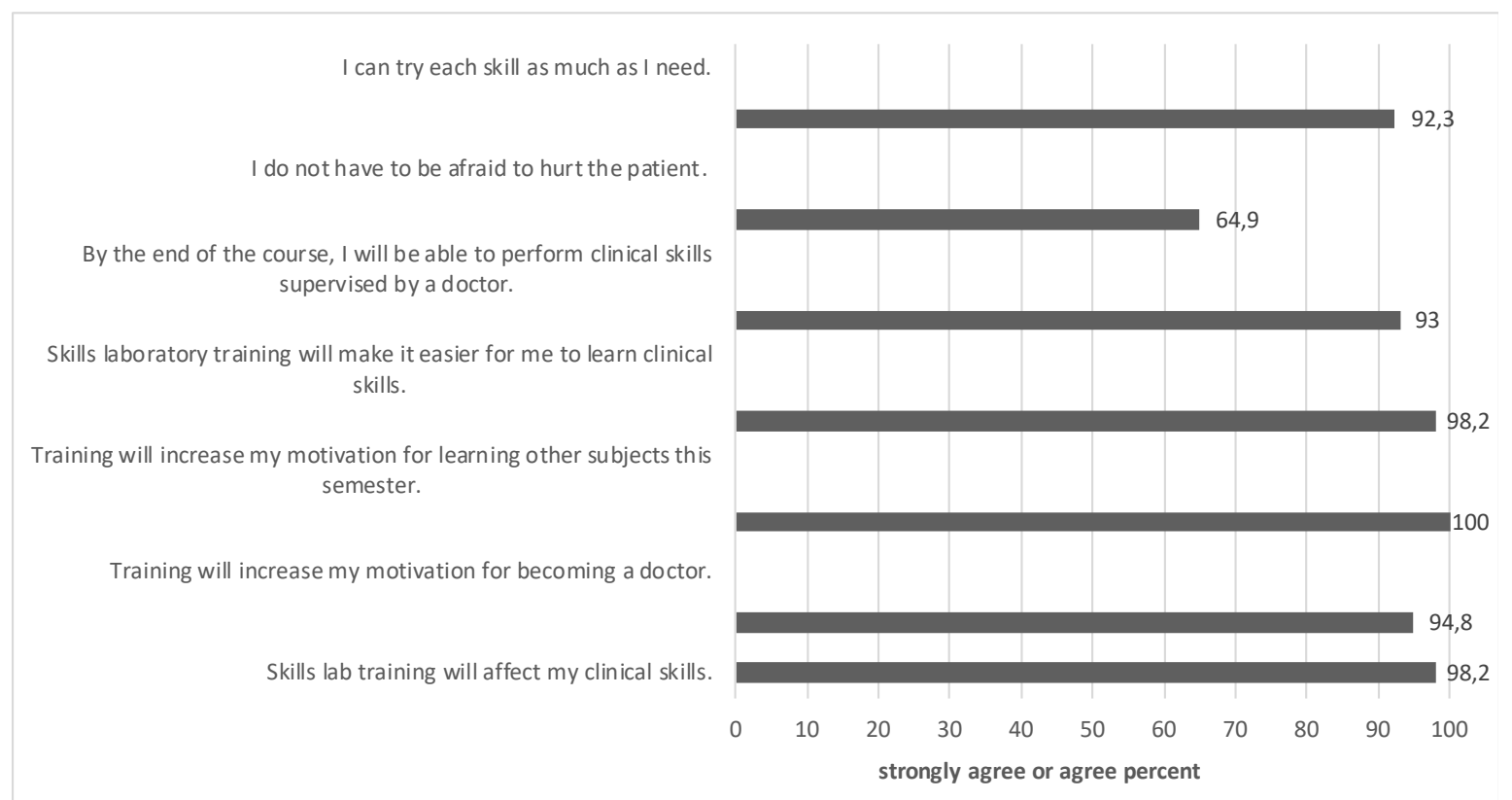

All 6th year students who only participated in surgical internship were included for this study. The practical course included eight basic clinical skills, chosen for this study, were taught in three different training sessions, each lasting for two hours. In the first session, suture practice was trained. Venous access, arterial access, intradermal and intramuscular injection and central venous cannulation were trained in the second session. The third session included male and female urinary catheterization, nasogastric tube placement and rectal examination.

The age distribution was homogeneous and sex ratios were similar. Providing training and data collection was carried out by the same coordinator so that the possibility of any bias that could have arisen from different executives was eliminated.

At the beginning of the training, simple clinical background information for each clinical skill was provided by the tutors. After that, the tutors demonstrated the procedures in a stepby-step manner prior to practice. The students then, under the supervision of the tutors, practiced the skills in similar clinical settings using manikins at the CSL. They were allowed to repeat the procedures as many times as they want until performing the skills competently. This is done by the availability of enough manikins and providing sufficient materials for training. The whole training took place at an interactive skills lab affiliated with Jordan University Hospital which utilized trained simulation patients and different models.

\section{Data Collection}

This study was planned as a cross-sectional survey. Data was collected using two anonymous questionnaires, which were modified from previously published studies to compare our results with others.19 The first questionnaire was distributed and collected before the beginning of the training sessions and the second questionnaire after the training was completed.

The first questionnaire consisted of general items identifying the students' attitude, expectations regarding skills laboratory training (SLT), and exploring their confidence level with similar items conducted at the second questionnaire. These were investigated as outcome measures. The questionnaire utilized a rating scale ranging from 1 point to 4 points. In addition, students were asked to self-evaluate their skills on a ten point scale in both questionnaires.

\section{Statistical Analysis}

Descriptive statistics of the results were computed as frequencies (count and percent), Mean \pm Standard Deviation and Median depending on the variable studied. Fisher-FreemanHalton exact test was used for differences between before and after training about distributions of the answers. The differences between before and after training were evaluated using the Mann-Whitney $U$ test with regard to performance score. A P value less than 0.05 was defined as statistically significant. All computations were performed with use of the PASW (ver. 18) program.

\section{Results}

57 volunteer students (27 female, 30 male) answered the baseline questionnaire and 29 students (14 female, 15 male) answered the follow-up questionnaire. Ages of the students were similar to each other ( $\min 23$, maximum 25 ).

\section{Students' expectations and attitude towards skills laboratory before training}

All the invited students $(n=57)$ who were in the beginning of their surgical clerkship attended at the beginning and filled the first questionnaire which was distributed before the training sessions. It contained items exploring students' expectations towards SLT. The students answered these items according to a 4-points Likert scale ranging from strongly agreed to strongly disagreed (Figure 1).

Almost all students strongly agreed or agreed that training in skills laboratory would increase their motivation for learning 
Figure 2. Students' expectations and attitude towards skills laboratory after training ( $n=29)$ (My expectations for skills laboratory training are)

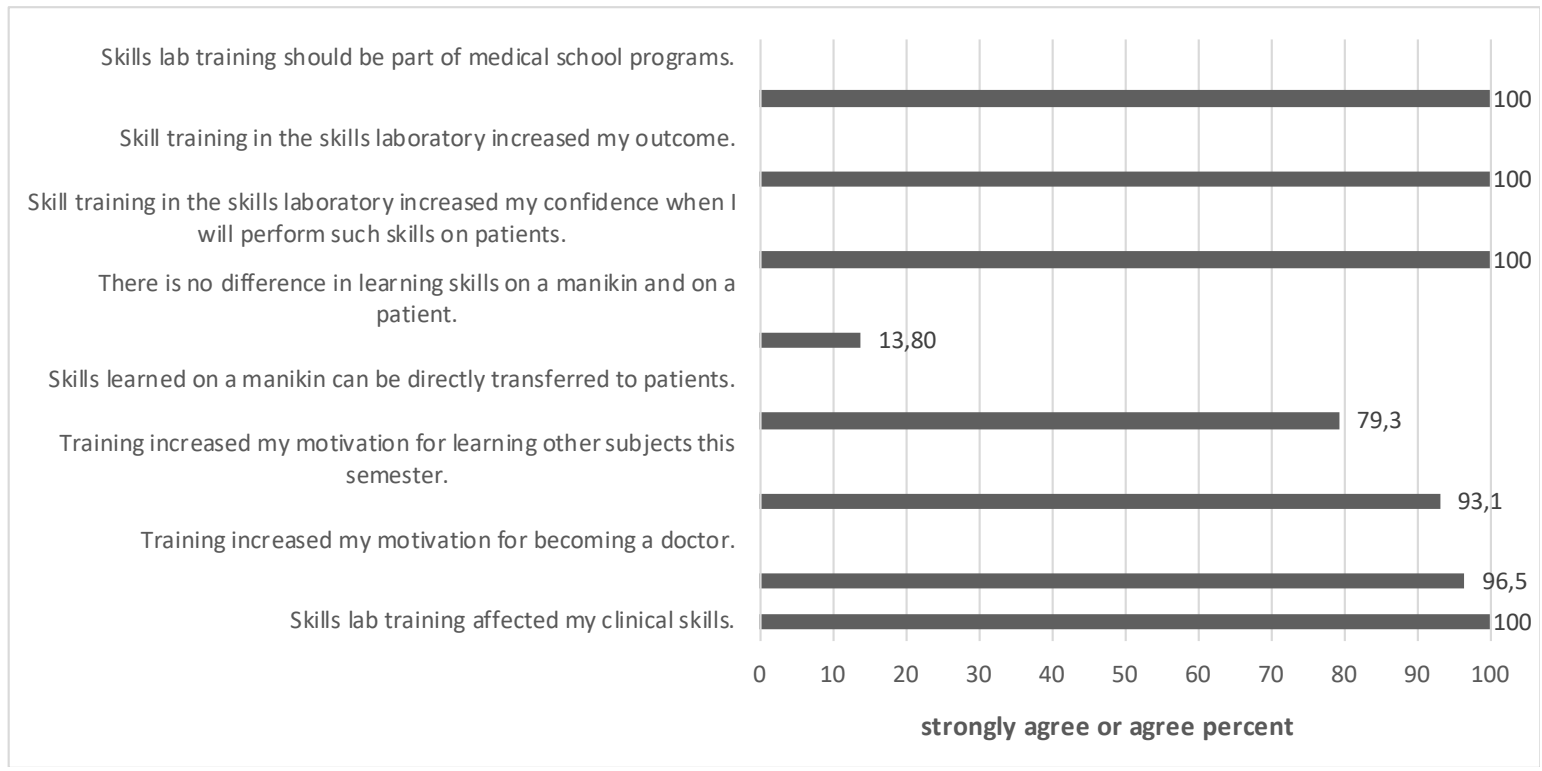

other subjects (100\%), would affect their clinical skills and would make it easier to gain them (98\%). In addition, most of them believed that training would increase their motivation for becoming a doctor (94\%) and expected that they would be able to perform clinical skills by the end of the course $(93 \%)$.

Students' expectations and attitude towards skills laboratory after training

At the end of the training, 29 students (50.9\%) had completed all training sessions and fulfilled the second questionnaire which also contained similar items that determined the students' perception towards skills laboratory after training. The answers were also according to a 4-points Likert scale ranging from strongly agreed to strongly disagreed (Figure 2).

After training, all students also strongly agreed or agreed that SLT affected their clinical skills (100\%). In addition; most students informed that training increased their motivation for learning other subjects (93\%) and for becoming a doctor (96\%). These results met what students expected before training. Further, the majority of them believed that skills learnt on manikins could be transferred to patients (79\%).

When the students were asked about learning of skills on manikins and on real patients, $13.8 \%$ believed that there was no difference, while others disagreed (disagreed or strongly disagreed). This reveals that the majority of students supposed that there was a difference between these two learning environments as the learning on manikins provided a safe and controlled environment to perform skills for the first time. Further, it allowed repeating of the procedures many times. All students stated that training at CSL increased their confidence and outcome $(100 \%)$. In addition, all of them suggested that SLT should be a part of the medical curriculum (100\%).

\section{Confidence level}

The students were asked to determine their confidence level about performing the selected procedural skills. Their answers were according to a 4-points Likert scale ranging from Not confident to Able to do independently (Table 1).

Before training the percentage of students who were Not confident was significantly higher $(P<0.001)$ for all selected skills. But after training, for the "Suture practice", "Arterial access" and the "Male and female urinary catheterization" the percentages of students who were somewhat confident, Very confident and Able to do independently were found to be significantly higher $(P<0.001)$. In addition, when we investigated the answers of "venous access", "Nasogastric tube placement" and the "Rectal examination" after training, it was found that the percentage of students who were Very confident and Able to do independently were significantly higher $(P<0.001)$.

After training of "Central venous cannulation", the percentages of students who were somewhat confident and Able to do independently were found to be significantly higher $(P<0.001)$. Furthermore, the percentage of students who were Able to do independently was also significantly higher after the training of "Intradermal and intramuscular injection" ( $P<0.001)$. Thus, there is an overall improvement in students' confidence level after training.

\section{Performance level}

When we investigated the students' performance level, we asked them to self-evaluate themselves on a 10 points scale before and after training. The mean score for the performance level of each clinical skill was significantly higher after training ( $P<0.001$ for each skill) (Table 2).

\section{Discussion}

In this study we investigated the effectiveness of CSLS on the acquisition of basic clinical skills by undergraduate medical students in the course of SLT, and we also explored students' perception towards skills training. Our results showed that 
Table 1. Comparison of before and after training responses.

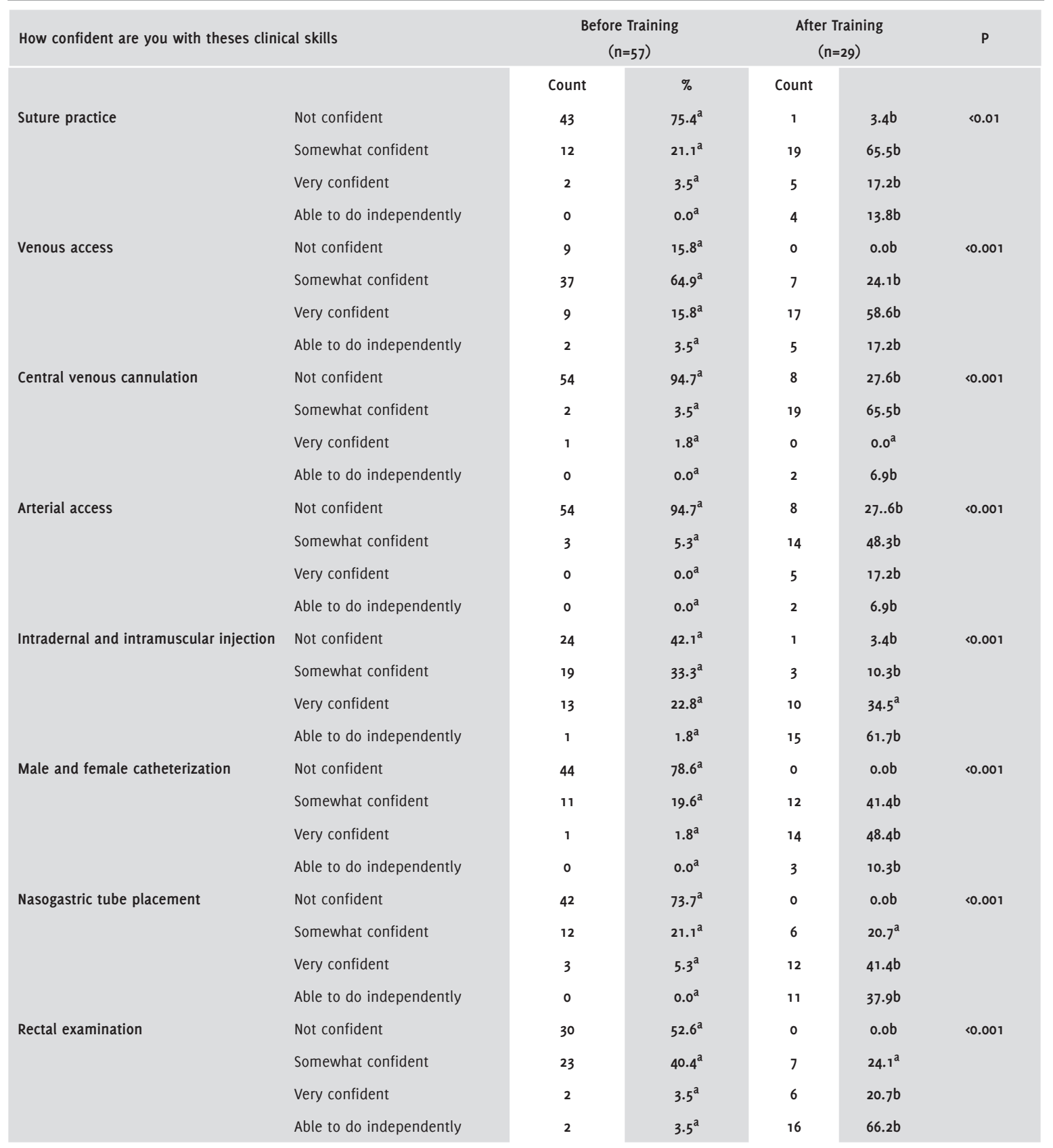

* Different letters which are located on the percentages indicate significant differences between before and after.

SLT has a valuable effect on students' performance level and it increased their outcome confirming previous findings by Remmen et al. ?

In addition, students perceived skills training highly to increase their motivation for learning and for becoming a doctor. This was congruent with other studies which found that students had good expectations and highly evaluated training in CSLS. ${ }^{19-20}$ In the present study, there was a significant increase in students' confidence level in performing clinical skills after practical course supporting previous studies as well. ${ }^{19,21-22}$

Before the training sessions, our data showed lower overall performance scores by medical students. This is probably due to the limited hands-on experience of basic skills during clerkships, as the students become anxious and fear harming patients when they have to apply first actual performance on real patients. ${ }^{23}$ In addition, limited exposure to patients and limited opportunity to practice the clinical skills during clinical rotations may also have a role. Indeed, in medical schools which depend heavily on clerkships' experience to train basic clinical skills, students' performances have been unsatisfactory. ${ }^{24-25}$ This indicates that adequate basic skills training cannot be achieved only by clerkship experience. ${ }^{8}$

In a systematic review, Lynagh et al. showed that clinical skills training at the CSL lead to improvements in performance level compared to traditional training. " This goes parallel to 
our results which showed that students' scores after training were significantly higher and there was an increase in their proficiency as well. This finding suggests that SLT leads to improvement in students' skills compared to the traditional "see one, do one" approach provided by bedside teaching. ${ }^{13}$

In fact, CSLs facilitate skills training and create a safe and controlled environment for medical students to acquire basic clinical skills; they also allow students to receive feedback about their performance and give the opportunity to repeat the procedures until they become competent before progressing to clerkships. Thus, SLT prepares undergraduate students more effectively to perform practical skills in the actual clinical practice and increases patients' safety. ${ }^{18,26}$

Our results showed that a majority of the students believed that the skills trained in CSL could be transferred to patients. This confirms other findings revealing that basic clinical skills such as intravenous cannulation and nasogastric intubation can be transferred from skills laboratory settings to be applied to real patients. ${ }^{13,18}$ Thus, the gap between preclinical and clinical phase can be overcome.
The fact that a number of students who were in the beginning of their surgical clerkship failed to complete the training sessions constitutes a limitation of our study. Having detected the presence of some students who disagreed or strongly disagreed with many of the questions constitutes another limitation. Additionally, other limitations may include the fact that the differences between different levels of medical school were not evaluated, the lack of randomization, and the diminished number of participants during the follow-ups.

In conclusion, the overall picture of this study reflects the deficiencies of medical students in acquiring adequate competence in performing basic clinical skills during their clerkships. We have shown in the present study that students' performance was significantly improved after training in the CSL. This underlines the need for skills lab implementation in medical schools and to be an integral part of the medical curriculum. Further studies should be undertaken to investigate the maintenance of skills performance after skills laboratory training and transference into real practice.

Table 2. . Descriptive values of performance score tof clinical skills on before and after training.

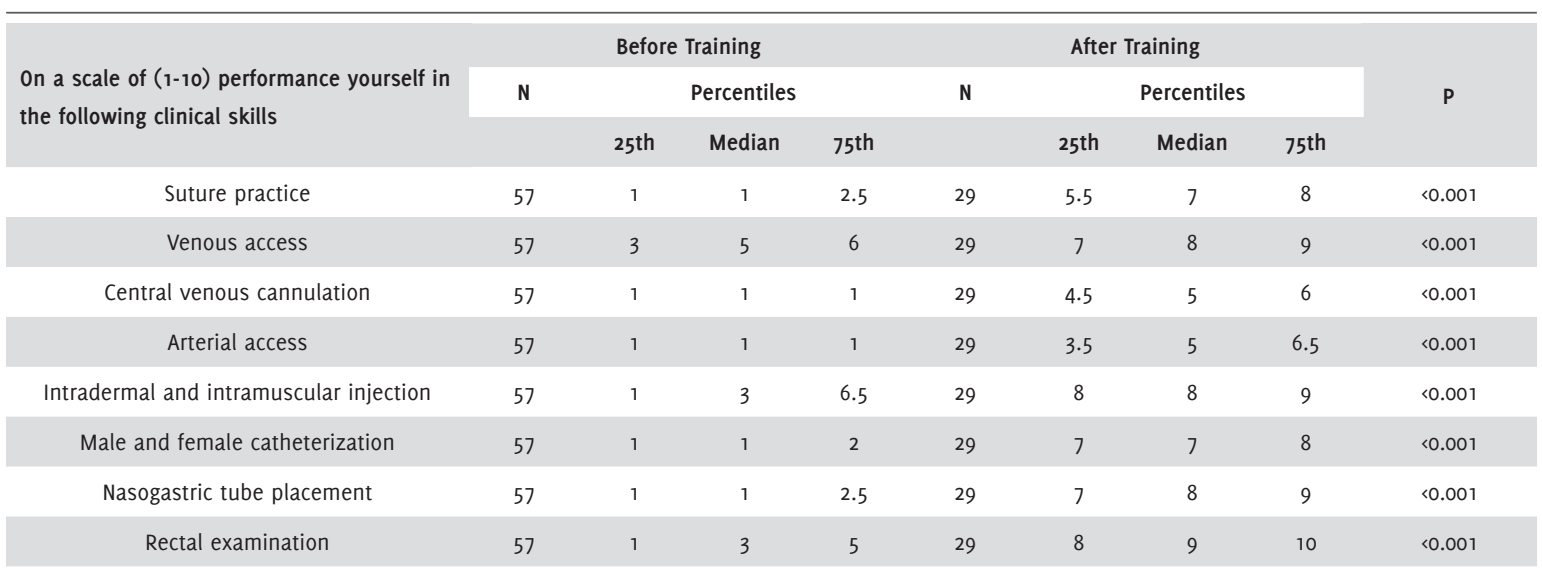




\section{References}

1. Epstein RM, Hundert EM. Defining and assessing professional competence. JAMA. 2002 Jan 9; 287(2): 226-35.

2. Cooke M, Irby DM, Sullivan W, Ludmerer KM. American medical education 100 years after the Flexner report. N Engl J Med. 2006 Sep 28; 355(13): 133944.

3. Scalese RJ, Obeso VT, Issenberg SB. Simulation technology for skills training and competency assessment in medical education. J Gen Intern Med. 2008 Jan; 23(Suppl 1): 46-49.

4. Elnicki DM, van Londen J, Hemmer PA, Fagan M, Wong R. U.S. and Canadian internal medicine clerkship directors' opinions about teaching procedural and interpretive skills to medical students. Acad Med. 2004 Nov; 79(11): 1108-13.

5. Gordon JA, Pawlowski J. Education on-demand: the development of a simulator-based medical education service. Acad Med. 2002 Jul; 77(7): 751-2.

6. Eyal L, Cohen R. Preparation for clinical practice: a survey of medical students' and graduates' perceptions of the effectiveness of their medical school curriculum. Med Teach. 2006 Sep;28(6):e162-70.

7. Remmen R, Scherpbier A, van der Vleuten C, Denekens J, Derese A, Hermann I, et al. Effectiveness of basic clinical skills training programmes: a cross-sectional comparison of four medical schools. Med Educ. 2001 Feb;35(2):121-8.

8. Remmen R, Derese A, Scherpbier A, Denekens J, Hermann I, van der Vleuten $C$, et al. Can medical schools rely on clerkships to train students in basic clinical skills? Med Educ. 1999 Aug;33(8):600-5.

9. Buckley S, Zamora J. Effects of participation in a cross year peer tutoring programme in clinical examination skills on volunteer tutors' skills and attitudes towards teachers and teaching. BMC Med Educ. 2007 Jun 28;7:20. 10. Paskins Z, Kirkcaldy J, Allen M, Macdougall C, Fraser I, Peile E. Design, validation and dissemination of an undergraduate assessment tool using SimMan $®$ in simulated medical emergencies. Med Teach. 2010 Jan;32(1):e12-7. 11. Lynagh M, Burton R, Sanson-Fisher R. A systematic review of medical skills laboratory training: where to from here? Med Educ. 2007 Sep;41(9):87987.

12. Akaike M, Fukutomi M, Nagamune M, Fujimoto A, Tsuji A, Ishida $K$, et al. Simulation-based medical education in clinical skills laboratory. J Med Invest. $2012 \operatorname{Jan} ; 59(1-2): 28-35$
13. Herrmann-Werner A, Nikendei C, Keifenheim K, Bosse HM, Lund F, Wagner $\mathrm{R}$, et al. "Best practice" skills lab training vs. a "see one, do one" approach in undergraduate medical education: an RCT on students' long-term ability to perform procedural clinical skills. PLoS One. 2013 Sep 25;8(9):e76354.

14. Ziv A, Ben-David S, Ziv M. Simulation based medical education: an opportunity to learn from errors. Med Teach. 2005 May; 27(3):193-9.

15. Bugaj TJ, Nikendei C. Practical Clinical Training in Skills Labs: Theory and Practice. GMS J Med Educ. 2016 Aug; 33(4): Doc63.

16. Bradley P, Postlethwaite K. Setting up a clinical skills learning facility. Med Educ. 2003 Nov; 37 Suppl 1: 6-13.

17. Du Boulay C, Medway C. The clinical skills resource: a review of current practice. Med Educ. 1999 Mar; 33(3): 185-91.

18. Lund F, Schultz JH, Maatouk I, Krautter M, Möltner A, Werner A, et al. Effectiveness of IV cannulation skills laboratory training and its transfer into clinical practice: a randomized, controlled trial. PLoS One. $2012 \mathrm{Mar} ; 7(3): \mathrm{e} 32831$. 19. Nielsen DG, Moercke AM, Wickmann-Hansen G, Eika B. Skills Training in Laboratory and Clerkship: Connections, Similarities, and Differences. Med Educ Online 2003 Dec;8(1):4334.

20. da Costa PM, Santos J, Maio R, Santos A, Paredes F. The role of a basic surgical skills laboratory as viewed by medical students (6th year). Med Teach. 2001 Mar;23(2):176-180.

21. Swamy M, Sawdon M, Chaytor A, Cox D, Barbaro-Brown J, McLachlan J. A study to investigate the effectiveness of SimMan ${ }^{\circledR}$ as an adjunct in teaching preclinical skills to medical students. BMC Med Educ. 2014 Nov 19;14:231.

22. Swamy M, Bloomfield TC, Thomas RH, Singh H, Searle RF. Role of SimMan in teaching clinical skills to preclinical medical students. BMC Med Educ. 2013 Feb 10;13:20.

23. Sarikaya 0 , Civaner M, Kalaca S. The anxieties of medical students related to clinical training. Int J Clin Pract. 2006 Nov;60(11):1414-8.

24. Remmen R. Unsatisfactory basic skills performance by students in traditional medical curricula. Med Teach. 1998 Jan;20(6):579-82.

25. Ringsted C, Schroeder TV, Henriksen J, Ramsing B, Lyngdorf P, Jønsson V, et al. Medical students' experience in practical skills is far from stakeholders' expectations. Med Teach. 2001 Jul;23(4):412-416

26. Blohm M, Krautter M, Lauter J, Huber J, Weyrich P, Herzog W, et al. Voluntary undergraduate technical skills training course to prepare students for clerkship assignment: tutees' and tutors' perspectives. BMC Med Educ. 2014 Apr 4;14:71.

\section{Acknowledgments}

None of the authors shows any acknowledgments during the investigation or publication of this article.

\section{Conflict of Interest Statement at Funding}

None of the authors shows any conflicts of interest during the investigation or publication of this article.

\section{Author Contributions}

Conception and design the work/idea: AMA, OA. Collect data/obtaining results: AMA, RA, AA, SA, OA. Analysis and interpretation of data: AMA, HA, OA. Write the manuscript: AMA, HA, RA, AA, SA, OA, MA, IM, OA. Critical revision of the manuscript: AMA, OA. Approval of the final version: AMA, HA, RA, AA, SA, OA, MA, IM, OA. Statistical Advice: AMA, HA, OA. Administrative of technical advice AMA, OA.

Cite as:

Abualhayja'a AM, Ankarali H, Alyacoub R, Abudayeh A, Alsaoud S, Alsaeidi 0M, Alsmady M, Massad I, Alimoglu 0. Sixth Class Students' Performance and Confidence Levels Before and After Training in Clinical Skills Laboratories. Int J Med Students. 2017 Jan-Apr;5(1):26-31. 